Terbit online pada laman web jurnal : http://e-journal.sastra-unes.com/index.php/JIPS

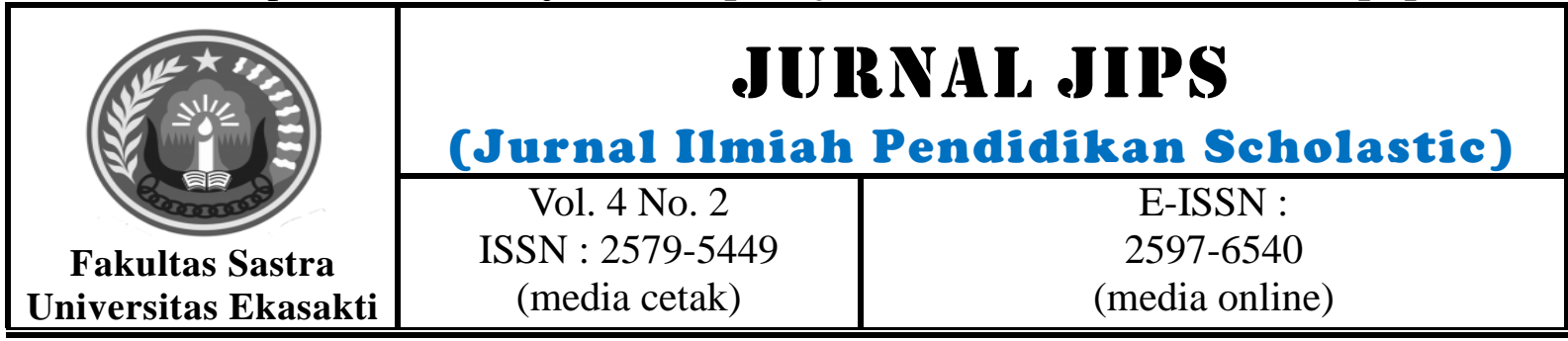

\title{
EFEKTIVITAS PELAYANAN PENGUJIAN KENDARAAN BERMOTOR PADA DINAS PERHUBUNGAN KOTA SAWAHLUNTO
}

\author{
Fera Mutia \\ Sekolah Tinggi Ilmu Administrasi(STIA) ADABIAH
}

\begin{abstract}
Efektivitas kerja organisasi sangat tergantung dari efektivitas kerja dari orang-orang yang bekerja didalamnya. Sangat sulit untuk mengukur efektivitas kerja, karena penilaiannya sangat subjektif dan sangat tergantung pada orang yang menerima pelayanan tersebut. Kesukarannya terletak pada penarikan generalisasi yang akhirnya berlaku umum dan dapat diterima oleh setiap orang. Dalam penyelenggaraan pelayanan publik, aparat pemerintah sangatlah bertanggungjawab dalam memberikan pelayanan maksimal kepada masyarakat sebagai wujud dari penciptaan kesejahteraan masyarakat. Salah satu bentuk pelayanan yang diberikan oleh Dinas Perhubungan yaitu pelayanan pengujian kendaraan bermotor
\end{abstract}

Keywords: Efektivitas, Pelayanan Publik, Kendaraan Bermotor

(C) 2020Jurnal JIPS

\section{INTRODUCTION}

Pemerintah banyak mendapat sorotan publik terutama dalam hal pelayanan yang menuntut aparatur negara sebagai pelayan masyarakat memberikan pelayanan sebaik baiknya menuju good governance, sedangkan masyarakat Indonesia sendiri semakin kritis dalam menginginkan pelayanan yang maksimal dari pemerintah. Oleh sebab itu, substansi administrasi sangat berperan dalam mengatur dan mengarahkan seluruh kegiatan organisasi pelayanan dalam mencapai tujuan.

Salah satu tantangan yang dihadapi pemerintah adalah bagaimana mereka mampu melaksanakan kegiatan secara efektif dan efisien, karena selama ini pemerintah sebagai pemberi layanan kepada masyarakat diidentikkan dengan kinerja yang berbelit-belit, struktur yang tambun, penuh dengan kolusi, korupsi dan nepotisme, serta tak ada standar yang pasti. Sejumlah patologi tersebut menjadi hambatan luar biasa untuk dapat mewujudkan sebuah pelayanan yang memuaskan masyarakat. Pengujian kendaraan bermotor merupakan salah satu sector pelayanan publik yang berperan penting dalam menunjang kelancaran mobilitas masyarakat untuk beraktivitas di sektor-sektor lain. Pelayanan pengujian kendaraan bermotor merupakan pemeriksaan pada kondisi kendaraan yang dilakukan oleh penguji apakah kendaraan tersebut memenuhi persyaratan layak jalan atau tidak, termasuk kelengkapan surat-surat kendaraan bermotor yang merupakan kewenangan dari Dinas Perhubungan. Dari pemeriksaan kondisi fisik kendaraan tersebut, maka sangat dibutuhkan pelayanan dalam kelancaran pengujian kendaraan bermotor itu sendiri.Dinas Perhubungan selaku Dinas yang memberikan pelayanan Pengujian Kendaraan Bermotor dituntut untuk selalu memberikan pelayanan yang baik kepada pengguna

Jurnal JIPS (Jurnal Ilmiah Pendidikan Scholastic) Vol. 4 No. 2 (2020) ISSN : 2579-5449

This work is licensed under a Creative Commons Attribution-NonCommercial 4.0 International License. 
kendaraan bermotor angkutan barang agar mereka mau melakukan uji kelayakan kendaraan. Jenis - jenis kendaraan yang wajib di uji adalah mobil barang, mobil bus, mobil sewa, mobil penumpang, mobil pick up, taksi dan semua jenis truk. Dasar hukum pengujian berkala kendaraan bermotor adalah sebagai berikut :

a.Undang-undang Nomor 22 Tahun 2009, Pasal 49, tentang Pengujian Kendaraan Bermotor

b.Keputusan Menteri Perhubungan Nomor KM.48 Tahun 2004 tentang Pengujian Berkala Kendaraan Bermotor

c.Keputusan Menteri Perhubungan Nomor KM.48 Tahun 2004 tentang Pengujian Berkala Kendaraan Bermotor, Pasal 3.

d.Peraturan Menteri Perhubungan Republik Indonesia Nomor PM 133 tahun 2015 tentang Pengujian Kendaran Bermotor.

e.Peraturan Daerah Kota Sawahlunto Nomor 09 Tahun 2007 tentang Pelayanan Pengujian Kendaraan Bermotor.

Pelaksanaan Undang-Undang Nomor 22 Tahun 2009 tentang Lalu Lintas dan Angkutan Jalan, khusus dalam menjalankan pelayanan pengujian kendaraan bermotor oleh Dinas Perhubungan Kota Sawahlunto, merupakan langkah preventif. Dinas Perhubungan Kota Sawahlunto menempatkan transportasi sebagai bagian dari kebutuhan masyarakat. Pelayanan kepada masyarakat dalam hal ini pemilik kendaraan bermotor angkutan barang diperlukan suatu kinerja pelayanan publik yang baik agar tercipta tujuan yaitu kepuasaan pengguna jasa pengujian kendaraan bermotor.Kesadaran masyarakat terhadap hak dan kewajibannya untuk memperoleh berbagai jenis pelayanan, termasuk bidang transportasi merupakan tantangan dan tanggung jawab yang besar bagi Dinas Perhubungan dalam menciptakan keterbukaan dan kemudahan bidang transportasi serta kemudahan mengakses berbagai informasi mengenai transportasi melalui media yang ada.Berdasarkan pengamatan sementara yang dilakukan peneliti, bahwa Dinas Perhubungan Kota Sawahlunto dalam melaksanakan pelayanan pengujian kendaraan bermotor masih mempunyai permasalahan, antara lain: (1) Sumber daya manusia masih kurang dalam hal pengujian kendaraan bermotor, (2) Belum adanya gedung pengujian kendaraan bermotor yang memadai, (3) alat pengujian kendaraan bermotor yang tidak lengkap, (4) Masih kurang optimalnya pelayanan yang diberikan kepada masyarakat.Hal ini sangat menarik untuk dipelajari lebih jauh, terutama untuk menemukan penyebabnya dan cara yang tepat untuk mengatasinya. Berdasarkan latar belakang tersebut, penelitian ini akan dipusatkan pada Unit Pengujian Kendaraan Bermotor dengan judul penulisan "EFEKTIVITAS PELAYANAN PENGUJIAN KENDARAAN BERMOTOR PADA DINAS PERHUBUNGAN KOTA SAWAHLUNTO"

\section{RESEARCH METHODS}

Perumusan masalah dalam penulisan ini adalah bagaimana efektivitas pelayanan pengujian kendaraan bermotor pada Dinas Perhubungan Kota Sawahlunto? Sesuai dengan perumusan masalah tersebut di atas, maka tujuan

penelitian ini adalah untuk mengetahui efektivitas pelayanan pengujian kendaraan bermotor pada Dinas Perhubungan Kota Sawahlunto.

\section{CONCLUSION}

Efektivitas merupakan gambaran keberhasilan dalam mencapai sasaran yang telah ditetapkan. Berdasarkan pengertian tersebut, maka efektivitas menggambarkan seluruh siklus input, proses, dan output yang mengacu pada hasil guna daripada suatu organisasi, program

atau kegiatan yang menyatakan sejauh mana tujuan (kualitas, kuantitas, dan waktu) telah dicapai.

Untuk pencapaian efektivitas pelayanan organisasi harus mengetahui sumberdaya yang diwakili organisasi, seorang pemimpin harus bisa

Jurnal JIPS (Jurnal Ilmiah Pendidikan Scholastic) Vol. 4 No. 2 (2020) ISSN : 2579-5449

This work is licensed under a Creative Commons Attribution-NonCommercial 4.0 International License. 
mengubah persepsi, mendesain kembali organisasi yang meliputi perencanaan, filosofis dan orientasi tim, semangat kerja kelompok dan menghasilkan produk yang bermutu.

Dengan demikian dapat dikatakan bahwa efektivitas pelayanan aparat adalah tercapainya suatu tujuan yang dilakukan oleh aparat dalam pelayanan sesuai dengan ketentuan yang telah ditetapkan.Menurut Sondang P. Siagian tentang Efektivitas Pelayanan antara lain:

1. Waktu, yaitu mampu tepat waktu dalam bekerja serta cekatan dan cepat dalam memberikan pelayanan terhadap customer. Dari hasil temuan yang ada dilapangan dapat disimpulkan bahwa untuk waktu pelayanan yang dilakukan pada pengujian kendaraan bermotor sudah tergolong memuaskan dengan pengerjaan yang cekatan.

2. Kecermatan, yaitu dalam memberikan pelayanan harus secara mendetail dan terarah agar tidak terjadi kesalahan. Dari hasil temuan yang ada dilapangan bagaimana kecermatan pelayanan di Pengujian Kendaraan Bermotor Dinas Perhubungan Kota Sawahlunto dapat disimpulkan bahwa dalam memberikan pelayanan pegawai pada unit pengujian kendaraan bermotor sudah cukup cermat. Dengan kecermatan tersebut, resiko kecelakaan kendaraan angkutan orang dan barang di Kota Sawahlunto bisa berkurang.

3. Gaya pemberian layanan, yaitu bagaimana cara kebiasaan pemberi pelayanan dalam membuat rasa nyaman kepada pelanggan. Dari hasil temuan yang ada dilapangan bagaimana gaya pemberian layanan di Pengujian Kendaraan Bermotor Dinas Perhubungan Kota Sawahlunto dapat disimpulkan bahwa dalam memberikan pelayanan kepada masyarakat mengutamakan kenyamanan dengan pelayanan dan keramahan pegawainya.Dari ukuran efektivitas pelayanan pengujian kendaraan bermotor di atas dapat terlihat pelayanan di pengujian kendaraan bermotor yang ditinjau dari waktu pelayanan, kecermatan pelayanan dan gaya pemberian pelayanan sudah cukup memuaskan.

Dari hasil penelitian yang dilakukan pada unit Pengujian Kendaraan Bermotor Dinas Perhubungan Kota Sawahlunto, didapat data kendaraan sebagai berikut:

Tabel 1 Taman Kendaraan Bermotor

\begin{tabular}{|l|l|l|l|l|l|}
\hline No. & Jenis Kendaraan & \multicolumn{1}{|c|}{ Umum } & T. Umum & Dinas & Jumlah \\
\hline 1 & Mobil Penumpang & 16 & & & $\mathbf{1 6}$ \\
\hline 2 & Bus & 37 & 14 & 7 & $\mathbf{5 8}$ \\
\hline 3 & Mobil Barang & 690 & 661 & 35 & $\mathbf{1 3 8 6}$ \\
\hline Total & & $\mathbf{7 3 4}$ & $\mathbf{6 7 5}$ & $\mathbf{4 2}$ & $\mathbf{1 4 6 0}$ \\
\hline
\end{tabular}

Sumber : Dinas Perhubungan (Pengujian Kendaraan Bermotor) 2019

Dari data diatas dapat dilihat bahwa jumlah kendaraan yang wajib uji tergolong cukup banyak, Pengujian terhadap kendaraan bermotor dilakukan dua kali dalam setahun atau enam bulan sekali. Artinya, dengan jumlah kendaraan yang wajib uji sebanyak 1460 dilakukan pengujian sebanyak 2920 kali ditambah lagi dengan kendaraan yang numpang uji.

Tabel 2 Faktor Pendukung dan Faktor Penghambat

\begin{tabular}{|c|l|l|}
\hline No. & Kualifikasi Pelaksana dan Peralatan/Perlengkapan & Keterangan \\
\hline 1 & Memiliki kompetensi penguji kendaraan bermotor & Kurang \\
\hline 2 & $\begin{array}{l}\text { Pendidikan minimal SLTA Jurusan IPA/SMK jurusan } \\
\text { Otomotiv/mesin }\end{array}$ & Cukup \\
\hline 3 & Bisa mengopersikan Komputer & Kurang \\
\hline 4 & Mengetahui tentang elemen kendaraan dan mesin & Kurang \\
\hline 5 & Gedung Uji kendaraan bermotor & Tidak ada \\
\hline 6 & Alat Uji kendaran bermotor & Tidak ada \\
\hline
\end{tabular}

Jurnal JIPS (Jurnal Ilmiah Pendidikan Scholastic) Vol. 4 No. 2 (2020) ISSN : 2579-5449

This work is licensed under a Creative Commons Attribution-NonCommercial 4.0 International License. 


\begin{tabular}{|l|l|l|}
\hline 7 & Kalibrasi Alat uji & Tidak ada \\
\hline 8 & Sistem informasi pengujian kendaraan bermotor & Kurang \\
\hline 9 & Kendaraan Uji Keliling & Tidak ada \\
\hline
\end{tabular}

Sumber data : Dinas Perhubungan (Diolah sendiri)

Berdasarkan tabel diatas dapat disimpulkan bahwa pengujian kendaraan bermotor dalam segi sumber daya manusia maupun sarana dan prasarana belum bisa dikatakan efektif. Dengan kekurangan tersebut, maka sangat dibutuhkan pelayanan yang baik. Berbicara pelayanan publik di Unit Pengujian Kendaraan Bermotor pada Dinas Perhubungan Kota Sawahlunto, tidak terlepas dari Efektivitas pelayanan tersebut. Kendala yang Mempengaruhi Efektivitas Pelayanan Pengujian Kendaraan Bermotor Dinas Perhubungan Kota Sawahlunto
Menurut Tangkilisan (2005:64) menguraikan beberapa faktor yang mempengaruhi efektivitas adalah:

Faktor Internal yaitu Produktivitas organisasi atau output merupakan suatu ukuran atas penggunaan sumber daya dalam suatu organisasi yang dapat dilihat dari pendidikan dianggap penting dan mengembangkan sumber daya manusia. Dari hasil temuan yang ada dilapangan dapat disimpulkan bahwa Sumber daya manusia belum sesuai dengan pendidikan untuk Pengujian Kendaraan Bermotor.

Tabel 3 Tingkat Pendidikan Pegawai, keadaan Agustus.

\begin{tabular}{|c|l|c|c|}
\hline No & \multicolumn{1}{|c|}{ Tingkat Pendidikan } & Jumlah & Presentase \\
\hline 1 & Tamat SLTA/ sederajat & 35 & $72,00 \%$ \\
\hline 2 & Tamat D3 PKB & 1 & $0,02 \%$ \\
\hline 3 & Tamat S1 & 9 & $18,75 \%$ \\
\hline 4 & Tamat S2 & 3 & $6,25 \%$ \\
\hline & Jumlah & 48 & $100 \%$ \\
\hline
\end{tabular}

Sumber : Dinas Perhubungan Tahun 2019 (diolah)

Dari data tabel 3, memperlihatkan bahwa tingkat pendidikan pegawai adalah sedang, hal ini terlihat dari persentase yang dominan yaitu pada jenjang pendidikan SLTA sebanyak 72,00 $\%$ dan D3 PKB hanya $0,02 \%$ sementara yang dapat menikmati Perguruan Tinggi hanya $25 \%$. Berdasarkan data tersebut pendidikan pegawai perlu perhatian, apalagi latar belakang untuk pengujian kendaraan bermotor hanya 1 orang.

Tabel 4

Keadaan Pegawai berdasarkan Pangkat dan Golongan, keadaan Agustus.

\begin{tabular}{|c|c|c|c|}
\hline No & Golongan & Jumlah & Presentase \\
\hline 1 & Pembina Tk.1/ IV.b & 2 & $4,17 \%$ \\
\hline 2 & Pembina/ IV.a & 6 & $12,5 \%$ \\
\hline 3 & Penata/ III & 10 & $20,8 \%$ \\
\hline 4 & Pengatur/ II & 30 & $62,5 \%$ \\
\hline & Jumlah & 48 & $100 \%$ \\
\hline
\end{tabular}

Sumber : Dinas Perhubungan Tahun 2019 (diolah)

Dari data tabel 4, memperlihatkan bahwa tingkat pangkat dan golongan pegawai adalah rendah, hal ini terlihat dari persentas yaitu pada tingkat Pembina sebanyak $16,67 \%$ dan Penata hanya $20,8 \%$ sementara yang tingkat yang dominan tinggi hanya pengatur yaitu $62,5 \%$. Berdasarkan data tersebut pangkat dan golongan pegawai dalam melakukan pelayanan publik perlu perhatian.
a.Faktor Eksternal berupa Efektivitas organisasi dalam bentuk keberhasilannya menyesuaikan diri dengan perubahan perubahan di dalam dan di luar organisasi. Dari hasil temuan yang ada dilapangan Pengujian kendaraan bermotor saat ini belum mampu mengikuti perkembangan karena belum memiliki sarana dan prasarana yang memadai.

Jurnal JIPS (Jurnal Ilmiah Pendidikan Scholastic) Vol. 4 No. 2 (2020) ISSN : 2579-5449

This work is licensed under a Creative Commons Attribution-NonCommercial 4.0 International License. 


\section{Upaya dalam Mengatasi Kendala Efektivitas Pelayanan Pengujian Kendaraan Bermotor Dinas Perhubungan Kota Sawahlunto}

Upaya dalam mengatasi kendala pengujian kendaraan bermotor dinas Perhubungan Kota Sawahlunto dalam memberikan pelayanan kepada masyarakat. Menurut HA.S Moenir (2006:88) mengemukakan Upaya mengatasi kendala efektivitas pelayanan adalah dengan cara meningkatkan:

1. Kesadaran, dengan adanya kesadaran pada pegawai atau petugas, diharapkan dapat melaksanakan tugas dengan penuh keikhlasan, kesungguhan dan disiplin. Dari hasil temuan yang ada dilapangan pengujian kendaraan bermotor saat ini kesadaran petugas pelayanan sudah lumayan baik.

2. Aturan adalah perangkat penting dalam segala tindakan dan perbuatan orang. Dari hasil temuan yang ada dilapangan Pengujian kendaraan bermotor, aturan yang mengatur tentang Pengujian Kendaraan Bermotor sudah ada diatur dalam Peraturan Daerah. Namun Perda tersebut harus disosialisasikan kepada masyarakat agar masyarakat mengerti dengan aturan yang sudah ada dan tidak menjadikannya alasan untuk melakukan pelanggaran.

3. Organisasi merupakan perwujudan susunan organisasi, melainkan lebih banyak pada pengaturan dan mekanisme kerjanya yang harus mampu menghasilkan pelayanan yang memadai. Pengujian kendaraan bermotor merupakan bagian dari Dinas Perhubungan Kota Sawahlunto yang bertugas untuk melaksanakan uji kendaraan.

4. Kemampuan dan keterampilan

Kemampuan merupakan sifat atau keadaan seseorang dalam melaksanakan tugas atau pekerjaan atas ketentuan-ketentuan yang ada. Istilah yang "kecakapan" selanjutnya keterampilan adalah kemampuan melaksanakan tugas atau pekerjaan dengan menggunakan anggota badan dan pengetahuan kerja yang tersedia. Dari hasil temuan yang ada dilapangan Pengujian kendaraan bermotor saat ini sudah memiliki kemampuan dan keterampilan yang handal.

Sarana dimaksud disini adalah segala jenis pelayanan, perlengkapan kerja dan fasilitas lain yang berfungsi sebagai alat utama atau pembantu dalam pelaksanaan pekerjaan. Dari hasil temuan yang ada dilapangan Pengujian kendaraan bermotor saat ini belum mampu mengikuti perkembangan karena belum memiliki sarana dan prasarana yang memadai.

Dari hasil penelitian yang peneliti lakukan di Unit Pengujian Kendaraan Bermotor pada Dinas Perhubungan Kota Sawahlunto, tingkat pelayanan kepada masyarakat masih tergolong rendah. Pelayanan di pengujian kendaraan bermotor juga belum efektif karena tidak didukung oleh sarana prasarana dan sumber daya manusia.

Dari temuan efektivitas pelayanan pengujian kendaraan bermotor belum maksimal karena adanya kendala yang dipengaruhi oleh faktor internal dan faktor eksternal. Dimana faktor internal berupa sumber daya manusia yang belum sesuai dengan latar belakang pendidikannya. Dan faktor eksternal bersumber dari masih belum memadainya sarana dan prasarana.

Upaya yang dilakukan untuk mengatasi kendala-kendala efektivitas pelayanan pengujian kendaraan bermotor adalah dengan meningkatkan kesadaran petugas, menetapkan aturan yang mengatur, memperbaiki sistem organisasi, meningkatkan kemampuan dan keterampilan, meningkatkan sarana dan prasarana. 


\section{Bibliography}

Sondang P. Siagian. 2009. Manajemen Modern. Undang-Undang Nomor 22 Tahun 2009 tentang Jakarta: PT. Gunung Agung.

Lalu Lintas dan Angkutan Jalan

Tangkilisan, Nogi Hessel. 2005. Manajemen

Publik. Jakarta: PT. Gramedia

Widiasarana Indonesia

Jurnal JIPS (Jurnal Ilmiah Pendidikan Scholastic) Vol. 4 No. 2 (2020) ISSN : 2579-5449 